
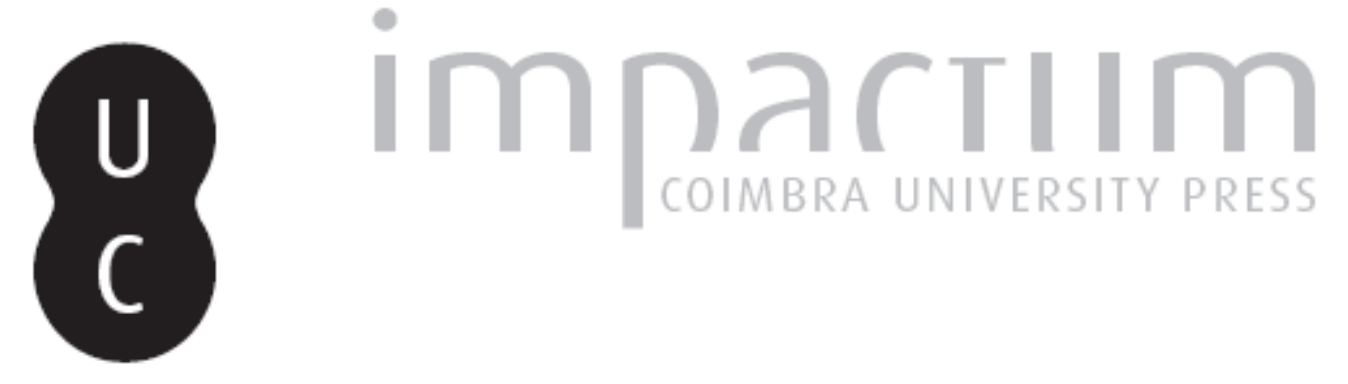

\title{
Fragmentos rossianos na arquitectura portuguesa
}

Autor(es): $\quad$ Figueira, Jorge

Publicado por: Imprensa da Universidade de Coimbra

URL persistente:

URI:http://hdl.handle.net/10316.2/44965

DOI:

DOI:https://doi.org/10.14195/0870-8584_12_2

Accessed : $\quad$ 26-Apr-2023 14:47:36

A navegação consulta e descarregamento dos títulos inseridos nas Bibliotecas Digitais UC Digitalis, UC Pombalina e UC Impactum, pressupõem a aceitação plena e sem reservas dos Termos e Condições de Uso destas Bibliotecas Digitais, disponíveis em https://digitalis.uc.pt/pt-pt/termos.

Conforme exposto nos referidos Termos e Condições de Uso, o descarregamento de títulos de acesso restrito requer uma licença válida de autorização devendo o utilizador aceder ao(s) documento(s) a partir de um endereço de IP da instituição detentora da supramencionada licença.

Ao utilizador é apenas permitido o descarregamento para uso pessoal, pelo que o emprego do(s) título(s) descarregado(s) para outro fim, designadamente comercial, carece de autorização do respetivo autor ou editor da obra.

Na medida em que todas as obras da UC Digitalis se encontram protegidas pelo Código do Direito de Autor e Direitos Conexos e demais legislação aplicável, toda a cópia, parcial ou total, deste documento, nos casos em que é legalmente admitida, deverá conter ou fazer-se acompanhar por este aviso.

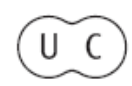




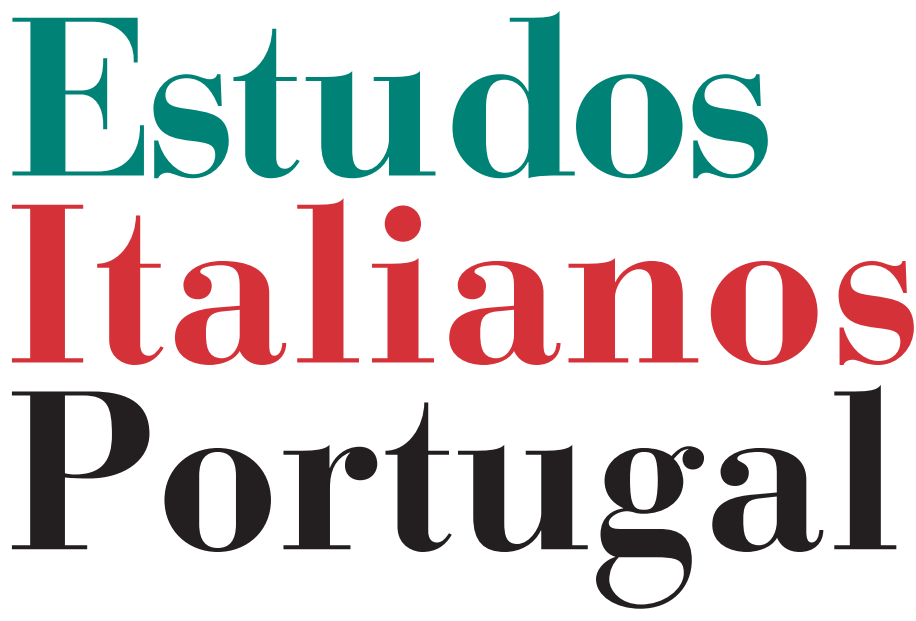

Instituto

Italiano

de Cultura

de Lisboa

Nova Série

No 12

2017 


\title{
FRAGMENTOS ROSSIANOS \\ NA ARQUITECTURA PORTUGUESA
}

\author{
Jorge FigueirA*
}

ESTE TEXTO pretende situar a repercussão da arquitectura italiana no contexto português contemporâneo a partir de um nome: Aldo Rossi. Em diferentes momentos e intensidades, outras figuras têm uma assinalável presença, na teoria e na prática. Vittorio Gregotti e Giorgio Grassi ou, na história da arquitectura, Bruno Zevi e Leonardo Benevolo, são nomes que ganharam familiaridade no contexto português.

No entanto, Aldo Rossi, figura maior da arquitectura das últimas décadas do século XX, deixou uma marca em Portugal, particularmente nas décadas de 1970 e 1980. É sobre este contexto que este artigo incide, sinalizando também o ressurgimento do interesse teórico e historiográfico em Rossi que foi materializado no trabalho de doutoramento do autor, apresentado em 2009, na Universidade de Coimbra, com o título A Periferia Perfeita. Pós-modernidade na arquitectura portuguesa. Anos 60-Anos 80 (publicado pela Caleidoscópio em 2014).

Não é fácil, no entanto, construir uma narrativa linear que situe Aldo Rossi no contexto português. Propõe-se, em alternativa, cinco fragmentos, que em conjunto traçam um possí-

*Licenciado em arquitectura pela Faculdade de Arquitectura da Universidade do Porto (1992) e doutorado em arquitectura pela Universidade de Coimbra (2009). É director e professor auxiliar do Departamento de Arquitectura da Faculdade de Ciências e Tecnologia da Universidade de Coimbra. É investigador do Centro de Estudos Sociais, UC.jfigueir@darq.uc.pt 
vel mapa rossiano. Em Portugal, ao contrário do que sucedeu em Itália ou em Espanha, os discípulos nunca formaram uma escola; ou, visto do outro lado, a escola da tendenza nunca conseguiu formar muitos discípulos. A tendenza - uma união das expressóes racionalistas da história da arquitectura que Rossi elabora como uma série de coincidências relidas no contexto contemporâneo ${ }^{1}$ - tem por cá uma expressão avulsa, fragmentada.

$\mathrm{Na}$ verdade, seria importante recuperar os trabalhos de alunos entre o final da década de 1970 e meados da década de 1980, nas Belas Artes do Porto e de Lisboa, depois Faculdades de Arquitectura, para se ter uma leitura mais ampla desse impacto. No entanto, a exposição Depois do Modernismo (1983) e principalmente a 2. a Exposição Nacional de Arquitectura. Anos 80 (1989) permitem ver como, nesse período, a presença de Rossi é recorrente, em formalismos que reiteradamente apelam ou citam motivos rossianos.

Uma advertência inicial: uma certa secura ou despojamento que apraz à arquitectura portuguesa, também no período estudado, não pode ser confundida directamente com uma influência de Rossi. De facto, a arquitectura portuguesa usa e revê-se na economia de meios expressivos, o que explica o gosto que perdura pela arquitectura moderna, principalmente na sua matriz racionalista. É um gosto que se confunde com uma necessidade: os meios escassos são projectados numa imagem despojada, às vezes entendida como minimalista. Na arquitectura dos anos 1970, esta economia expressiva poucas vezes se refere a Rossi, com as excepçóes que serão indicadas. De facto, o "racionalismo exaltado" de Boullée, traduzido para o nosso tempo por Rossi, tem por cá uma expressão limitada e vigiada. Dir-se-ia que a distância que Rossi cria com a arquitectura moderna impediu o entusias-

${ }^{1}$ Cf. Aldo Rossi, "L'architettura della ragione come architettura di tendenza”, Scritti scelti sull'architettura e la città, Torino, CittàStudiEdizioni, [1975] 1978, pp. 370-378. 
mo do Porto; e o complexo enunciado teórico impediu uma apropriação em Lisboa. A excepção é José Charters Monteiro, como se verá, ex-aluno do arquitecto italiano e responsável pela tradução de A arquitectura da cidade / L'architettura della città, em 1977. Em qualquer caso, pode-se afirmar que os formalismos rossianos, aculturados e apropriados, pairam livremente na produção portuguesa dos anos 1980.

\section{FRAGMENTO 1}

Numa entrevista publicada na revista Arquitectura, em 1979, Nuno Portas dá conta das transformaçōes que estão a ocorrer na cultura arquitectónica, e os seus reflexos em Portugal, nomeadamente por referência a Aldo Rossi, temendo o "retorno do grande projecto urbano, iluminista ou neoclássico, baseado em memórias formais da cidade tradicional, seguindo um método de colagem, quase sempre tão arbitrário quanto insensato" ${ }^{2}$. Quando afirma que "na chamada tendência deu-se um salto, na passagem do momento analítico para o momento criativo, e esse salto é que é extremamente contestável" ${ }^{\prime \prime}$, Portas evoca a passagem do tipo para a imagem que marca a evolução da abordagem rossiana.

Como escreveu Rafael Moneo, no percurso de Aldo Rossi há um permanente balanço entre o conhecimento e o sentimento ${ }^{4}$, podendo-se constatar que há uma progressão de uma ênfase no conhecimento, nos anos 1960, para uma ênfase no sentimento, a partir de 1976, quando viaja para a América. L'architettura della città, livro publicado em 1966

${ }^{2}$ Nuno Portas, "Entrevista a Nuno Portas" [por José M. Fernandes e José Lamas], Arquitectura, 135, 1979, p. 62.

${ }^{3} \mathrm{Ib} ., \mathrm{p} .67$.

${ }^{4}$ Cf. , Rafael Moneo, "Aldo Rossi", Theoretical anxiety and design strategies in the work of eight contemporary architects, trad. Gina Cariño Cambridge, Massachussetts, London, The MIT Press, Barcelona, Actar, 2004, p. 105. 
e reflexo de conferências e liçôes que Rossi foi realizando, é essencialmente motivado pelo lado do conhecimento. Posteriormente, a imagem vai dilacerar o tipo ou, se se quiser, o sentimento vai falar mais alto que o conhecimento. A publicação de Autobiografia scientifica em Nova Iorque, 1981, traduz essa evolução. Se L'architettura della città aspirava a uma possibilidade normativa, a Autobiografia scientifica concentra-se na mundivisão do seu autor. A procura da essência vai até ao essencial - a vida é mais importante que a arquitectura: "Avrei potuto indifferentemente intitolare questo livro Dimenticare l'architettura perché posso parlare di una scuola, di un cimitero, di un teatro ma è più preciso dire la vita, la morte, l'immaginazione" 5 .

É essa transição de uma via científica para a arte ou para a autobiografia que Portas repudia na entrevista de 1979, em coerência com o seu discurso e práticas desde os anos 1960. Ao enunciar e criticar a colagem põe em causa, centralmente, o modelo rossiano: “O que se está a dar é ainda uma forma de colagem [...]. Porque a colagem era uma maneira de fazer projectos por exemplo, no curso do Rossi há 10 anos em Milão, onde a tendência tem a sua origem e em que se faziam colagens com recortes de plantas de edifícios de várias épocas" ${ }^{\text {. }}$.

Com a tendenza, Rossi imagina uma perpetuação progressista das formas existentes e portanto formula uma espécie de fim da história: "já foi tudo inventado"; "os problemas são sempre os mesmos". A arquitectura é para Rossi uma arte combinatória ${ }^{7}$, sem recuo nem avanço, um jogo de derivação

\footnotetext{
${ }^{5}$ Aldo Rossi, Autobiografia scientifica, Milano, Pratiche Editrice, [1981] 1999, p. 113.

${ }^{6}$ Nuno Portas, cit., p. 66.

7 "Con l'introduzione del meccanismo analogico e della citazione, l'architettura di Rossi assume tutti i caratteri di un'arte combinatoria”. Cf. Patricia Montini Zimolo, "Per un'educazione al progetto", Pisana Posocco; Gemma Radicchio; Gundula Rakowitz (ed.), Care architetture. Scritti su Aldo Rossi, Torino, Umberto Allemandi \& C., 2002, p. 105.
} 
a partir de mitologias e figuraçôes locais. É esse o sentido do trágico em Rossi: uma eterna repetição das mesmas imagens recolocadas, um cul-de-sac poético dada a impossibilidade prática de sair da história da cidade.

Mesmo se o seu segundo livro se chama $A$ Cidade como Arquitectura (1969), Portas nunca foi rossiano.

\section{Fragmento 2}

Em 1976 teve lugar o Seminário Internacional de Arquitectura en Compostela (I SIAC) ${ }^{8}$, dirigido por Aldo Rossi, com a presença de Álvaro Siza e a participação de um grupo de jovens arquitectos portugueses, entre os quais Eduardo Souto de Moura e José Charters Monteiro, um momento singular de aproximação portuguesa à abordagem rossiana.

Em 1979, as alteraçôes em curso na cultura arquitectónica fazem-se sentir no "Encontro de Aveiro". Adoptando uma terminologia rossiana, os organizadores propõem-se discutir a prática disciplinar ${ }^{9}$ e será notado que o debate já não envolve as questóes políticas que tinham sido centrais em 1969, o encontro anterior. Não é só o país que mudou, a arquitectura tem agora outros referentes. $\mathrm{O}$ que tende a unir as intervenções é o entendimento da autonomia da arquitectura, para usar o termo rossiano que é referido ${ }^{10}$, que se traduzirá no progressivo abandono do discurso social e na oposição aos métodos científicos de projecto. No caso específico de Lisboa, o que está em causa é uma ruptura com os pressupostos

${ }^{8}$ Cf. I Seminario Internacional de Arquitectura en Compostela, "Proyecto y ciudad histórica”, I SIAC, Colegio Oficial de Arquitectos de Galicia, 1977.

9 "Informação", Arquitectura, 4. a s., 132, 1979, p. 76.

10 "Dois ou três vectores fundamentais caracterizam a quase globalidade dos projectos", escreve João Luís Carrilho da Graça: "O entendimento da arquitectura como actividade cultural autónoma, a constatação de que a actividade do arquitecto consiste em conformar espaços, dar-lhes forma [...], o entendimento da arquitectura como lin-

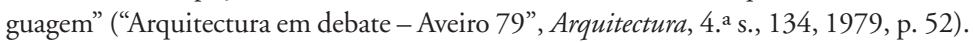


científicos da geração onde pontua Nuno Portas. É disso que Pedro Vieira de Almeida se dá conta ao comentar os projectos apresentados no Congresso:

Alguns dos quais se percebiam como elegantes objectos, e brilhantes exercícios de mão e gosto, afirmavam-se curiosamente desvinculados de qualquer circunstância responsabilizante, desde a formalização dos programas (que logo se propunham não discutir) passando por todo o processo do projecto, ausente, desprendidamente tecnocrático, até à definição do produto final, fechado, incapaz de um diálogo de apropriação com as populações ou com os sítios, desvinculado de quaisquer preexistências, com total desdém por preocupações sociológicas ou culturais. ${ }^{11}$

Para a nova geração, dir-se-ia, a atenção ao produto final substitui as interrogaçóes processuais. $\mathrm{O}$ desejo do desenho é mais forte que os resultados dos inquéritos. No lugar da ciência aspira-se à artisticidade das Belas Artes. Ao notar que a "intervenção urbanística volta a ser, ali, a do objecto acabado, rígido, definitivo" 12 , Vieira de Almeida parece involuntariamente fazer uma descrição do neo-racionalismo.

\section{Fragmento 3}

Em 1976, no número da L'Architecture d'Aujourd'Hui dedicado a Portugal, Gonçalo Byrne propõe o que intitula "quelques prémices pour une architecture nouvelle". Enuncia uma ruptura com duas correntes - uma "italianisante" e outra "associée au développement touristique"13 - e abre o espaço

${ }^{11}$ Pedro Vieira de Almeida, "Arquitectura em debate - Aveiro 79”, Arquitectura, 4. ${ }^{\mathrm{a}}$ s., 134,1979 , p. 51.

${ }^{12} \mathrm{Ib}$.

13 Gonçalo Byrne, "Quelques prémices pour une architecture nouvelle", L'Architecture d'Aujourd'Hui [“Portugal”], 185, 1976 [2006], p. 32. 
de uma nova tendência, considerada "formalisme" pelos adversários, mas que "justement en agissant sur les mécanismes de la forme [...] se démarque du Mouvement Moderne" através "d'une action lucide, déssacralisante du langage de l'architecture et de ses systémes internes"14. Esta arquitectura nova move-se numa linha crítica cujo projecto se traduz no recurso à austeridade e à depuração. A principal fonte é a vanguarda moderna que é entendida como um regresso do censurado: "L'utilisation d'une poétique minimaliste préconisée par certains architectes, renvoie à des formes de l'architecture de l'architecture des années 20, curieusement éliminée pendant la dictature salazariste" 15 . No plano urbano, Byrne está próximo de uma formulação rossiana quando escreve sobre uma arquitectura que "elle-même devient une site", assumindo-se com a "fonction de germe séminal pour un tissu déqualifié en inversant la tradition qui exigeait que le projet s'intègre en continuité avec le milieu"16.

Esta mediação de elementos neo-modernistas e neo-racionalistas é patente no conjunto habitacional conhecido como "Pantera Cor-de-Rosa" (Chelas, Lisboa, 1971-1975), de Byrne e António Reis Cabrita. A Pantera integra elementos da cidade tradicional (a praça) e elementos da cidade moderna (a galeria). É um modelo híbrido e tipologicamente experimental que ao referenciar-se em arquétipos tem uma conotação neo-racionalista e ao assumir uma linguagem depurada - as paredes lisas e os caixilhos pintados - refere-se às experiências art deco e modernistas de Lisboa. É uma arquitectura económica, mas não na expressão formal e simbólica.

$\mathrm{O}$ desafio era levantar uma arquitectura significante, emblemática e cívica que pudesse escapar às insuficiências correntes da habitação social. Sendo um projecto contido e racional, é também exuberante na experimentação tipológica e

\footnotetext{
${ }^{14} \mathrm{Ib}$.

${ }^{15} \mathrm{Ib}$.

${ }^{16} \mathrm{Ib}$, p. 33.
} 
espacial. Elementos monumentalizadas, como as colunas ampliadas nas esquinas ou a praça, são um claro aceno à arquitectura de Rossi, e remetem para uma urbanidade antiga que Byrne e Reis querem reintroduzir na experiência moderna.

FRAGMENTO 4

José Charters Monteiro é o responsável pela obra mais próxima da experiência rossiana em Portugal: o conjunto da Bela Vista (Setúbal, 1974-1981) é uma malha de quarteiróes hiperbolizados - depurados e agigantados - que remetem para os arquétipos da cidade tradicional (praças, esquinas, escadarias) ${ }^{17}$. À maneira de Rossi, a Bela Vista é uma efabulação sobre tipos tradicionais exponenciados formalmente.

Numa das viagens que fez na altura a Portugal, Rossi visitou a Bela Vista e propôs a construção de uma estrutura longa e rectilínea - o "Bacalhau", como ficará conhecido -, um projecto depois desenvolvido por vários arquitectos ${ }^{18}$ mas que não foi construído. Implantar-se-ia ao longo de uma via paralela à costa como edifício-muro franqueado por três pórticos, programa misto, perfil redesenhado da cidade, um monumento feito de paredes, janelas e portas.

Em vista aérea, a Bela Vista é uma retícula de escala monumental que se destaca da cidade. Cada unidade é resultado da adição simples de dois fogos com galeria dispostos à volta de um espaço quadrangular de 40 metros.

Parece tratar-se de um conjunto de quarteiróes, imprimindo o tradicional traçado da rua-corredor. $\mathrm{Na}$ verdade, trata-se de uma efabulação sobre este tipo, mais projecto do

${ }^{17}$ Cf. Jorge Figueira, "Monumentalidade e melancolia: a Bela Vista revisitada", $A$ noite em arquitectura, Lisboa, Relógio d'Água, 2007, pp. 162-167.

${ }^{18}$ Cf. José Charters Monteiro, "Uma construção na azul neblina da memória”, JA - Jornal Arquitectos, 174-175, 1997, pp. 28-32. O projecto é desenvolvido por vários arquitectos. Além de Aldo Rossi, Arduino Cantafora, Fabio Reinhart, Gianni Braghieri, José Charters Monteiro, José Sousa Martins, Max Bosshard. 
que reposição historicista. No interior de cada uma destas unidades do tipo quarteirão, sucedem-se espaços mediadores entre a casa e a rua, do tipo praça. A ordem precisa que o conjunto imprime ao território não impede a existência de um tecido intrincado de espaços, galerias e acessos. Pelo contrário, a adição modular dos quarteirōes permite o surgimento de diferenças e variações no interior do mais severo sistema compositivo.

Ao modo rossiano, a Bela Vista é um lugar do século XX em refluxo face ao novo. Como escreveu Rafael Moneo, "in Rossi's work there is a deliberate relinquishing of novelty" ${ }^{19}$. Este refluxo significa a adopção de uma temporalidade sustentada pelo que é permanente, pela memória comum, por uma ideia de colectivo. A arquitectura deve referir-se a valores cívicos, aspirar à gravidade do monumento. A cidade, entendida como arquitectura, é a nossa maior conquista; o sítio onde ganha sedimento o quotidiano e a memória colectiva se refaz. Para repercutir esta visão, o projecto deve fundar-se nos tipos que fizeram a cidade, de onde decorrerá a necessária invenção poética (ou arquitectónica, que é a mesma coisa). "Per chi oggi è convinto della necessità di una lettura dell'architettura fondata su principi logici" ${ }^{20}$, como enuncia Rossi em 1967 na sua "Introduzione a Boullée", esta é uma das ideais centrais: o recurso às tipologias como mecanismo de análise dos edifícios e matriz do projecto permite repercutir a memória da cidade, acrescentando-lhe novos estratos.

Na Bela Vista, a passagem abrupta da tipologia para a arquitectura, sem mediação ou estilo, aproxima o edifício da imagem da ruína. $\mathrm{O}$ conjunto ecoa esse discurso e prática, inscrevendo-se abertamente no poema rossiano. Pode ser ex-

${ }^{19}$ Rafael Moneo, "Aldo Rossi: The Idea of Architecture and the Modena Cemetery" [1976], trad. Angela Giral, Oppositions Reader, New York, Princeton Architectural Press, 1998, p. 124.

${ }^{20}$ Aldo Rossi, "Introduzione a Boullée", Scritti scelti sull'architettura e la città, p. 346. 
trapolada para o interior de um sonho: as praças como pátios conventuais; o depósito de água como torre do relógio; a perspectiva alongada de edifícios em repetição como racionalidade exaltada.

\section{FRAGMENTO 5}

No Porto, nos anos 1970 e 1980, a novidade de Rossi não entra com facilidade. $\mathrm{O}$ racionalismo reinventado da Escola do Porto segue paralelamente ao neo-racionalismo da tenden$z a$, com poucas intersecções.

Em meados dos anos 1960, Siza dá-se conta que a terceira via - que pressupunha uma mediação do moderno e da tradição - está esgotada. Nesse momento desaparecem os elementos convencionais ou tradicionais nas suas obras e começam a ser introduzidos - reinstalados, dir-se-ia - elementos de origem racionalista: coberturas planas; ênfase na repetição; variação extremada entre aberturas e planos cegos. Acontece aqui o que podemos chamar uma reinvenção do racionalismo. O programa SAAL (Serviço de Apoio Ambulatório Local) é o epicentro desta viragem, porque cria o quadro político e não só o gosto para que uma arquitectura despojada, económica e radical, possa surgir com sentido. Com esta inesperada deriva racionalista, o grupo do Porto demonstra uma fé na arquitectura que é perturbante, em tempos de crise das veleidades modernas.

É também neste quadro de revisitação livre do racionalismo que a obra de Souto de Moura começa a nascer, depois acrescentada de outras legitimidades e fontes. Aldo Rossi, particularmente.

A atenção de Souto de Moura aos temas que se colocavam na época, em particular a Rossi, foi relatada pelo próprio $^{21}$, mas é patente logo no artigo que publica em 1979,

${ }^{21}$ Cf. Eduardo Souto de Moura (a cura di Antonio Esposito), d'Architettura, 23, “Dopo Aldo Rossi”, 2004, pp. 185-191. 
"A cidade é funcional", onde refere implicitamente Rossi de L'architettura della città: "um objecto é tanto mais funcional, quanto melhor consegue ultrapassar a sua função específica"; e antecipa o Rossi da Autobiografia scientifica: "É entrar com nós próprios, com a cidade que temos, com as ruínas que temos"22.

O Relatório de Estágio de Souto de Moura (1981-1982), que inclui este texto, é generoso nas referências arquitectónicas, filosóficas, literárias e artísticas, lançadas como fragmentos de uma colagem pós-moderna. Uma citação de Henry Miller traduz o essencial: "Verdadeiramente não inventamos o que quer que seja. Pedimos emprestado e recriamos" 23 .

De facto, L'architettura della città integra uma crítica explícita a elementos estruturais do Movimento Moderno. O funcionalismo é descrito como ingénuo ${ }^{24}$, a partir da constatação que uma arquitectura menos motivada pela função, mais próxima de um tipo, pode ter mais vidas, consagrar vários programas, resistir ao tempo. Rossi pretende "superare il più o meno dichiriato funzionalismo che percorre, a partire da Vitruvio, tuto l'iter del pensiero architettonico"25, já que "la funzione non é che uno strumento di fronte all'experienza dell'architettura"'26.

$\mathrm{Na}$ complexa relação de Rossi com a arquitectura moderna, deve-se também acrescentar que o purismo característico da fase inicial da sua obra tem uma razão de ser distinta da depuração do que chama "razionalismo convenzionale" 27. Como escreve Daniele Vitale: "Le avanguardie cercavano

${ }^{22}$ Id., "A cidade é funcional", Jornal de Notícias, 30-1-1979, reed. Relatório de Estágio de Arquitectura de Eduardo Souto de Moura, texto policopiado, 1981-1982, p. 2.

${ }^{23}$ Ib., p. 9.

${ }^{24}$ Cf. "Crítica ao funcionalismo ingénuo", A arquitectura da cidade, trad. José Charters Monteiro, Lisboa, Edições Cosmos, 2001, pp. 56-60.

${ }^{25}$ Aldo Rossi, "Architettura per i musei”, Scritti scelti sull'architettura e la città, p. 325.

${ }^{26} I b .$, p. 336.

${ }^{27}$ Cf. Aldo Rossi, “Introduzione a Boullée”, p. 348. 
l'origine delle cose e l'origine era fatta coincidere com la purezza e l'idealità delle figure elementari. Rossi trova ed estrae tali figure dal reale, a volte trova lo scheletro" ${ }^{28}$. Ou seja, o despojamento que Rossi investiga não tem a ver com um higienismo formal de inspiração maquinista, mas significa o regresso a uma espécie de inocência exercida sobre o tempo passado. "Ciò che distingue i progetti di Aldo Rossi, ciò che in essi ancor oggi colpisce e afascina, è innazi tutto il loro radicalismo, la loro assolutezza. Essa viene da un processo di riduzione e scarnificazione delle forme", o que Daniele Vitale coloca em relação com um "stato di innocenza"29.

Quanto mais próximo do tipo, mais arquitectónico. É isso que Souto de Moura descobre precocemente no Mercado de Braga (1980-1984), organizado segundo a ideia de uma construção rectilínea que liga dois pontos da cidade. No limite, é um muro, num certo estado de inocência. Se o Mercado de Braga é um dispositivo que utiliza o mínimo de recursos formais, aquilo que significa no quadro rossiano é um máximo de expressão cívica: cada pilar é uma coluna; cada muro, uma ruína.

Neste sentido, Souto de Moura consegue evocar uma cultura central no final dos anos 1970, embora eliminando a monumentalidade que o neo-racionalismo usa. Da disciplina fica o espaço, a construção, a estrutura, o programa; e a cidade em estado de inocência.

No Mercado de Braga surge ainda um mecanismo que Souto de Moura irá usar recorrentemente: um neoplasticismo que inclui a ruína. A lógica moderna e cósmica da abordagem neoplástica integra a lógica pós-moderna da ruína como reflexo da obsolescência pós-industrial. Souto de Moura inaugura então uma improvável intersecção - numa linha - da cultura racionalista cara à Escola do Porto, com

${ }^{28}$ Daniele Vitale, "L'azzurro del cielo", Salvatore Farinato (org.), Per Aldo Rossi, Veneza, Marsilio, 1998, p. 56.

${ }^{29} I b . .$, p. 54. 
a cultura neo-racionalista entretanto assumida como pósmodernista.

Nos anos 1980, a partir do Teatro del Mondo (Veneza, 1979-1980), a fama de Aldo Rossi irá ter uma ascensão meteórica e uma queda aparatosa. 